\title{
Quality Assessment Criteria for Mobile Health Apps: A Systematic Review
}

\author{
Wilasinee HONGSANUN ${ }^{1}$ and Suppachai INSUK ${ }^{2, *}$ \\ ${ }^{1}$ Sukhothai Provincial Public Health Office, Sukhothai 64000, Thailand \\ ${ }^{2}$ Department of Pharmacy Practice, Faculty of Pharmaceutical Sciences, Naresuan University, \\ Phitsanulok 65000, Thailand
}

('Corresponding author's e-mail: suppachaii@nu.ac.th)

Received: 2 March 2019, Revised: 23 June 2019, Accepted: 14 July 2019

\begin{abstract}
Summative evidences on the criteria for user assessment of health apps are still limited. In order to determine an assessment method for mobile health apps, rigorous and appropriate criteria must be chosen. The aim of this study is to review the existing quality assessment criteria that are being used to assess the quality of mobile health apps focusing on users' perspectives. In addition, a procedure for the quality assessment of health apps is also presented.

A systematic review was conducted utilizing 5 databases; PubMed, ScienceDirect, Scopus, CENTRAL and IEEE Xplore from 2008 to 2017. Search terms were; "mHealth", "Applications", "iOS OR Android", "smartphones", "quality", etc. Papers that assessed the quality of health apps by users were selected. The PRISMA guideline was followed to complete the list of final studies. Likewise, a data extraction form was based on the PICO framework. From 6,514 studies, 69 studies met the eligibility criteria. Four hundred and forty-one quality assessment criteria for users were classified into 15 domains: Ease of use, Usability, Aesthetics, Connectivity, Functionality, Information, User satisfaction, Acceptability, Error occurrence, Motivation, Engagement, Data management, Undesirable events, Credentials and Security and privacy. An "ease of use" domain was found common in the included studies. The 15 domains were suggested as criteria for further study of the quality assessment and development of mHealth apps. Moreover, five recommended steps were presented for future research of quality of mobile health apps.
\end{abstract}

Keywords: Assessment, Systematic review, Mobile health apps, Quality, mHealth

\section{Introduction}

It is undeniable that smartphones increasingly become a crucial part of our lives. A significant number of people use smartphone apps for self-management of their health. There are 5 million apps available in two leading app stores Google Play Store (Android) and Apple App Store (iOS). In 2015, 3 billion mobile health apps were downloaded [1]. With such a large availability of apps, the possibility of launching low quality or harmful mobile health apps by some developers may lead to adverse effect for users. For instance, Acne App (iOS) and Acne Pwnder (Android) which falsely claimed that blue and red light therapy is an effective acne treatment were removed from the app marketplaces [2].

Mobile health apps are increasingly advanced with new technologies; however, they may not have been approved by health care providers or there may be no peer-review systems that exist before releasing these health apps through the app marketplaces. Although the users consider the quality of health apps from user ratings and reviews in the app marketplaces, there is no guarantee whether these reviews are reliable or not [3]. 
http://wjst.wu.ac.th

The United States Food and Drug Administration (US FDA) provides guidelines to regulate only mobile medical apps which are intended to be used as an accessory to a regular medical device or to transform a mobile platform into a medical device [4]. However, clinicians and patients are still concerned regarding other types of health apps that, without proper assessment systems, could pose a significant threat to users [5].

Currently, there is a lack of standardized assessment method for mobile health apps. Although there may be some systems, for instance, Psyberguide [6] and the American Psychiatric Association App Evaluation Model [7], that provide classification criteria of the apps, they only provide assessment guides for mental health apps. Moreover, summative evidences on the criteria for user assessment of health apps are still limited. In order to determine an assessment method for mobile health apps, rigorous and appropriate criteria must be chosen.

The objective of this systematic review is to review existing quality assessment criteria that are being used to assess the quality of mobile health apps focusing on users' perspectives. In addition, a procedure for the quality assessment of health apps is presented. In this study, we focus on mobile health apps in a broader sense, such as disease management, health and fitness, health information and other health-related apps to identify a wide variety of quality assessment criteria.

\section{Materials and methods}

\section{Search strategy}

With the research question: "What are the existing criteria used for assessing quality of mobile health apps?", 5 databases were searched: PubMed, ScienceDirect, Scopus, Cochrane Central Register of Controlled Trials (CENTRAL) and IEEE Xplore. Grey literature (literature that has not been formally published) [8] was searched from www.ntis.gov, www.mobileactive.org and www.opengrey.eu. The search time window was limited from July 2008 to December 2017 (the first app store launched in July, 2008). The search terms were divided into 5 groups and combined using the Boolean operator AND: 1. (health OR medical OR medication OR medications OR mHealth), 2. (app OR apps OR Application OR Applications), 3. (iOS OR Android), 4. (mobile OR mobiles OR smartphone OR smartphones OR "cell phone" OR "cell phones" OR "mobile device" OR "mobile devices"), 5. (quality OR criteria OR assess* OR evaluate* OR "rating scale" OR checklist OR “content analysis” OR framework).

\section{Eligibility criteria}

The inclusion criteria were 1. The studies that related to the evaluation or assessment of mobile health apps (any apps that intend to provide disease management, health and fitness, health information and other health-related apps), 2. The target groups of the apps were patients or general users, 3 . The full texts of the studies were published in English. On the other hand, the exclusion criteria were 1.The studies that focused on the effectiveness or development of the apps without quality assessment by users, 2 . The studies that allowed only the developers to assess the apps, 3. The studies that adopted the quality assessment tools from previously published studies without adaptation.

\section{Selection process}

This review followed the Preferred Reporting Items for Systematic Reviews and Meta-Analyses (PRISMA) statement guidelines to complete a list of final studies [9]. The studies were identified, screened, and selected based on specific inclusion and exclusion criteria by two independent reviewers (SI and WH).

First, all studies were screened based on titles and abstracts. The abstracts that met the inclusion criteria (focusing on types of apps and target groups) were included. If the abstracts did not provide sufficient information, the full texts of articles were assessed according to the eligibility criteria by both reviewers. Disagreement was resolved by discussion. Reference lists and citations of included studies were screened to identify additional relevant studies. The data from included studies were extracted and analyzed to generate the quality assessment criteria. 
http://wjst.wu.ac.th

\section{Data extraction}

The data extraction forms were developed based on the PICO framework [10]. The extracted data included: general characteristics of the studies, characteristics of mobile health apps, the procedure for quality assessment and the quality assessment criteria of mobile health apps. Data entered was automatically stored in an online spreadsheet and assessed for agreement by two reviewers. In the case of disagreement, consensus was established based on face to face discussion or on acquiring feedback from an external reviewer.

\section{Classification of the quality assessment criteria}

The quality assessment criteria of mobile health apps extracted from the studies were classified by two reviewers. Disease specific quality assessment criteria were excluded. The criteria were then independently classified from identified sources using two steps: 1 . The quality assessment criteria used in each study were grouped based on the similarity of the area or duplicated meaning of assessment. This provided the themes of assessment criteria. 2. All the themes of assessment criteria were grouped into the same quality domain. All discrepancies were resolved by discussion.

\section{Risk of bias of included studies}

The included studies were evaluated for their quality and risk of bias using a checklist. The checklist consisted of 8 questions with 8 as the maximum score where higher score represents lower risk of bias and higher quality of the study. The quality of each study was rated according to the corresponding items on the checklist [11]. The 8 questions were: consideration of the data collection time frame, the apps were fully downloaded for consideration based on its content, the clarity method of appraisal the app's quality, the clarity describe the methodology taken to search for appropriate apps, the clarity of the inclusion and exclusion criteria for app selection, the clarity identify the country where the search was conducted, definition of the targeted groups of users and provision of a list of the apps [11].

\section{Results}

\section{Studies identified}

Initially 6,514 studies were identified after excluding the duplicates. After screening the titles and abstracts, 205 full text articles were reviewed and 66 studies met the eligibility criteria. Three studies were included through screening the reference lists and citations. Thus, 69 studies were identified as relevant and were included in this review, as shown in Table 1. Figure 1 is a PRISMA flow diagram showing the number of studies identified in each database and the number of studies excluded $[9,12]$.

\section{Characteristics of included studies}

General characteristics of the 69 included studies are presented in Table 2. Fifty studies (73\%) used non-app development study design (cross sectional, experimental or RCT). Both Android and iOS platforms were evaluated in 26 studies $(38 \%)$. It was notable that 36 studies $(50 \%)$ involved disease specific or disease management apps. The target groups of the apps were both lay person users and healthcare providers in 46 studies $(67 \%)$. Moreover, the numbers of app assessors were varied, ranging from 2 to 3,977 (Mean 99.1 \pm SD 509.6). 


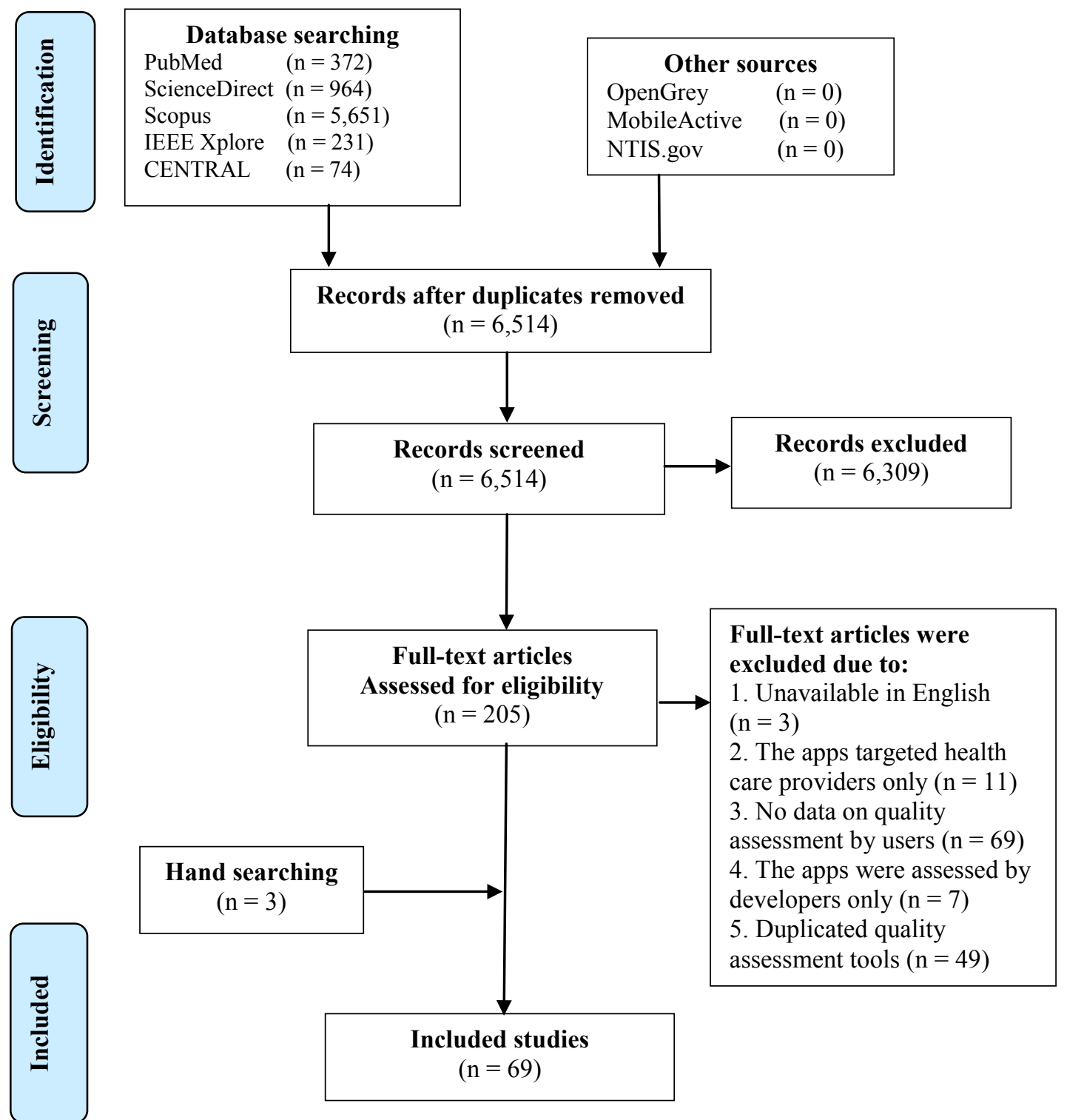

Figure 1 PRISMA flow diagram. 
Table 1 Included studies.

\begin{tabular}{|c|c|c|c|}
\hline Study design & Target groups of the apps & Platforms & Mobile Health apps for \\
\hline Non App-development [13] & Health care providers/Smokers & iOS & Smoking cessation \\
\hline App development [14] & Patients /General users & Android & Weight control \\
\hline Non App-development [15] & Health care providers/Patients & $\begin{array}{l}\text { iOS, Android, Blackberry } \\
\text {,Nokia/Symbian , and Windows } \\
\text { Mobile }\end{array}$ & Pain management \\
\hline Non App-development [3] & $\begin{array}{l}\text { Health care providers/Diabetes } \\
\text { patients }\end{array}$ & Android & Diabetes \\
\hline Non App-development [16] & Menopausal women & Symbian & $\begin{array}{l}\text { Recording symptoms and physical } \\
\text { activity }\end{array}$ \\
\hline Non App-development [17] & Health care providers/Patients & $\begin{array}{l}\text { iOS, Android, Blackberry and } \\
\text { Windows phone }\end{array}$ & Asthma \\
\hline Non App-development [18] & Health care providers/Patients & iOS, BlackBerry, and Android & Personal health records \\
\hline App Development [19] & General users (Arab) & Android & Diet Assisting \\
\hline Non App-development [20] & $\begin{array}{l}\text { Health care providers } \\
\text { /Colorectal diseases patients }\end{array}$ & $\begin{array}{l}\text { iOS, Android, Blackberry, } \\
\text { Nokia and Windows sites }\end{array}$ & Colorectal cancer \\
\hline Non App-development [21] & General users (Adolescents) & iOS, Android & $\begin{array}{l}\text { Daily diet app and exercise } \\
\text { activities app }\end{array}$ \\
\hline Non App-development [22] & $\begin{array}{l}\text { Health care providers/Patients / } \\
\text { General users }\end{array}$ & iOS, Android & HIV \\
\hline Non App-development [23] & Health care providers/Patients & Android & $\begin{array}{l}\text { Treatment of diseases/ Health } \\
\text { awareness/ Content diffusion/ Aid } \\
\text { for professionals }\end{array}$ \\
\hline Non App-development [24] & $\begin{array}{l}\text { Health care providers/Patients/ } \\
\text { General users }\end{array}$ & iOS, Android & $\mathrm{HIV} / \mathrm{STD}$ \\
\hline Non App-development [25] & $\begin{array}{l}\text { Health care providers/Patients / } \\
\text { General users }\end{array}$ & iOS & Cancer \\
\hline App development [26] & $\begin{array}{l}\text { Patients (adolescents with } \\
\text { cancer) }\end{array}$ & iOS & Pain Assessment \\
\hline App development [27] & $\begin{array}{l}\text { Patients with age-related } \\
\text { macular degeneration and } \\
\text { diabetic retinopathy }\end{array}$ & iOS & Monitoring of Visual Function \\
\hline Non App-development [28] & $\begin{array}{l}\text { Health care providers/Diabetes } \\
\text { patients aged } 50 \text { or older }\end{array}$ & iOS, Android & Diabetes \\
\hline App development [29] & Health care providers/Patients & Android & Knee rehabilitation \\
\hline Non App-development [30] & Health care providers/Patients & iOS, Android & Hepatitis \\
\hline App development [31] & $\begin{array}{l}\text { Coronary artery disease } \\
\text { patients }\end{array}$ & iOS, Android & Coronary artery disease \\
\hline Non App-development [32] & Health care providers/Patients & $\begin{array}{l}\text { iOS, Android, Nokia, } \\
\text { Blackberry, Samsung and } \\
\text { Windows }\end{array}$ & Hernia \\
\hline Non App-development [33] & Patients /General users & iOS, Android & $\begin{array}{l}\text { Mobile Personal Health Records } \\
\text { (PHRs) }\end{array}$ \\
\hline App development [34] & Health care providers/Patients & iOS, Android & Assessment pain intensity \\
\hline Non App-development [35] & Health care providers/Patients & iOS, Android & Stroke \\
\hline App development [36] & $\begin{array}{l}\text { Patients (the low-income } \\
\text { women) }\end{array}$ & $\mathrm{iOS}$ & $\begin{array}{l}\text { A counseling app to promote } \\
\text { interest in and awareness of long- } \\
\text { acting reversible contraceptive }\end{array}$ \\
\hline Non App-development [37] & Health care providers/Patients & iOS & Obesity management \\
\hline Non App-development [38] & Health care providers/Patients & $\mathrm{iOS}$ & Mental health \\
\hline Non App-development [39] & Health care providers/Patients & iOS, Android & General health apps \\
\hline App development [40] & Patients (children with DM) & Android & Games for diabetes education \\
\hline Non App-development [41] & Health care providers/Patients & Android & General medical apps \\
\hline Non App-development [42] & Health care providers/Patients & $\mathrm{iOS}$ & Stress management \\
\hline
\end{tabular}




\begin{tabular}{|c|c|c|c|}
\hline Study design & Target groups of the apps & Platforms & Mobile Health apps for \\
\hline Non App-development [43] & $\begin{array}{l}\text { Health care providers } \\
\text { /Patients (older adult) }\end{array}$ & Android & Management of headache \\
\hline Non App-development [44] & Health care providers/Patients & iOS, Android, Blackberry & Adherence apps \\
\hline Non App-development [45] & Adult bipolar disorder patients & Android & $\begin{array}{l}\text { Self-management of bipolar } \\
\text { disorder }\end{array}$ \\
\hline App development [46] & GDM patients & Android & $\begin{array}{l}\text { Gestational diabetes mellitus } \\
\text { management }\end{array}$ \\
\hline Non App-development [47] & Health care providers/Patients & iOS, Android & $\begin{array}{l}\text { Medication-related problems } \\
\text { (MRPs) }\end{array}$ \\
\hline Non App-development [48] & $\begin{array}{l}\text { Health care providers/General } \\
\text { users }\end{array}$ & iOS, Android & $\begin{array}{l}\text { Prevention of unintended } \\
\text { pregnancy }\end{array}$ \\
\hline Non App-development [49] & Health care providers/Patients & iOS & Menstrual cycle \\
\hline Non App-development [50] & Health care providers/Patients & iOS, Android, Blackberry & $\begin{array}{l}\text { Management of childhood } \\
\text { enuresis }\end{array}$ \\
\hline Non App-development [51] & Health care providers/Patients & iOS & $\begin{array}{l}\text { Depression apps, Smoking } \\
\text { cessation apps }\end{array}$ \\
\hline Non App-development [52] & Patients/General users & iOS, Android & $\begin{array}{l}\text { Diabetes, Depression, and Caring } \\
\text { for the elderly }\end{array}$ \\
\hline Non App-development [53] & General users & iOS & Knowledge and awareness \\
\hline Non App-development [54] & Health care providers/Smokers & $\mathrm{iOS}$ & Smoking cessations \\
\hline Non App-development [55] & $\begin{array}{l}\text { Health care providers/Patients / } \\
\text { General users }\end{array}$ & Android & $\begin{array}{l}\text { Health related behaviors apps and } \\
\text { Mental health apps }\end{array}$ \\
\hline App development [56] & Patients/ General users & iOS, Android & $\begin{array}{l}\text { Monitoring and awareness of } \\
\text { healthy eating }\end{array}$ \\
\hline Non App-development [57] & $\begin{array}{l}\text { Health care providers/Patients / } \\
\text { General users }\end{array}$ & iOS, Android & Breast cancer \\
\hline Non App-development [58] & $\begin{array}{l}\text { Health care providers/Patients / } \\
\text { General users }\end{array}$ & iOS, Android & Medication management \\
\hline Non App-development [59] & $\begin{array}{l}\text { Health care providers/General } \\
\text { users }\end{array}$ & iOS & Fitness and exercise apps \\
\hline Non App-development [60] & Health care providers/Patients & iOS, Android & Chronic pain \\
\hline Non App-development [61] & Health care providers/Patients & iOS, Android & Chronic Insomnia Disorder \\
\hline App development [62] & General users & Android & Mindfulness training and practice \\
\hline Non App-development [63] & Health care providers/Patients & Android & Physiotherapy for frozen shoulder \\
\hline App development [64] & Patients /General users & $\mathrm{iOS}$ & Drug information \\
\hline App development [65] & Patients & Android & Colonoscopy Preparation \\
\hline Non App-development [66] & $\begin{array}{l}\text { Health care providers/Patients / } \\
\text { General users }\end{array}$ & iOS & Cancer \\
\hline
\end{tabular}

Table 2 Study characteristics.

\begin{tabular}{lc}
\hline \multicolumn{1}{c}{ General characteristics } & Number of Studies (n= 69) \\
\hline \multicolumn{1}{c}{ Study design } & 19 \\
\hline App Development & 50 \\
\hline Non-App Development & \\
\hline \multicolumn{1}{c}{ Target groups of the apps } & 23 \\
\hline Lay person users only & 46 \\
\hline
\end{tabular}




\begin{tabular}{lc}
\hline \multicolumn{1}{c}{ General characteristics } & Number of Studies $(\mathbf{n}=\mathbf{6 9})$ \\
\hline \multicolumn{1}{c}{ Platforms } & 1 \\
\hline Symbian only & 15 \\
iOS only & 17 \\
Android only & 26 \\
iOS and Android & 10 \\
iOS, Android and others & \\
\hline \multicolumn{2}{c}{ Mobile Health apps for ${ }^{\mathrm{a}}$} \\
Mental health and addiction behaviors & 10 \\
Disease specific or disease management & 36 \\
General health behaviors & 24 \\
Not specified & 2 \\
\hline
\end{tabular}

${ }^{\mathrm{a}}$ More than one types of the apps were evaluated in some studies.

\section{Classification of quality assessment criteria of mobile health apps}

Four hundred and forty-one criteria from the 69 studies were grouped based on the similarity of the area of assessment. These were narrowed to 77 themes of quality assessment criteria after similar or duplicated meaning criteria were grouped together. Then, all 77 themes of criteria were clustered into 15 quality domains. Table 3 shows the list of the 15 domains: Ease of use, Credential, Usability, Aesthetics, Connectivity, Functionality, Information, Acceptability, User satisfaction, Error occurrence, Motivation, Engagement, Security and Privacy, Data management and Undesirable events. The "Ease of use" domain was the most common domain found in quality assessment of mobile health apps. Moreover, 9 out of 77 themes criteria were not classified into any domains: App size $(n=1)$ [42], Social influence $(n=1)$ [67], GPS $(\mathrm{n}=2)$ [17,48], Reduce health care cost $(\mathrm{n}=1)$ [60], HIPAA (the Health Insurance Portability and Accountability Act) compliance $(n=1)$ [44], Printing $(n=1)$ [50], Software support $(n=1)$ [51], Voluntariness $(n=1)[67]$ and ICE (In case of emergency) feature $(n=2)[17,18]$.

Table 3 Domains of quality assessment criteria.

\begin{tabular}{|c|c|c|}
\hline Name of domains & Quality assessment criteria of mobile health apps & $\begin{array}{l}\text { Number } \\
\text { of studies }\end{array}$ \\
\hline Ease of use & $\begin{array}{l}\text { Ease of use, Navigation, Gestural design, Learnability / Learning, Adherence } \\
\text { to literate principles of design plain language, Technical support throughout } \\
\text { the application }\end{array}$ & 62 \\
\hline Credentials & $\begin{array}{l}\text { Contact details, Authoritative, Medical professional involvement, } \\
\text { Endorsement of the app, Funding, Advertising policy, A credible source of } \\
\text { information }\end{array}$ & 51 \\
\hline Usability & $\begin{array}{l}\text { Usability, Purpose of the app, Usage intention, Effectiveness, Effectiveness } \\
\text { tested (claimed by app), Efficiency }\end{array}$ & 50 \\
\hline Aesthetics & User interface design, Aesthetics & 34 \\
\hline Connectivity & $\begin{array}{l}\text { Availability, Available in other languages, Inter-platform availability, } \\
\text { Support interoperability, Data entry, Interactivity and connectivity }\end{array}$ & 26 \\
\hline Functionality & $\begin{array}{l}\text { Functionality, Technology-enhanced features, Specificity of intervention, } \\
\text { Flexibility, Other data tracking }\end{array}$ & 26 \\
\hline
\end{tabular}


http://wjst.wu.ac.th

\begin{tabular}{|c|c|c|}
\hline Name of domains & Quality assessment criteria of mobile health apps & $\begin{array}{l}\text { Number } \\
\text { of studies }\end{array}$ \\
\hline Information & $\begin{array}{l}\text { Information, Content, Information provided in a clear and appropriate way } \\
\text { for the target audience, Complete and Concise information, Claims, } \\
\text { Currency, Perceived risk }\end{array}$ & 26 \\
\hline Acceptability & Acceptability, Worth recommending, Stimulate repeat use & 26 \\
\hline User satisfaction & User ratings & 25 \\
\hline Error occurrence & $\begin{array}{l}\text { Error, Navigational links were broken, Precision/ Accuracy, Unreliable } \\
\text { performance }\end{array}$ & 22 \\
\hline Motivation & $\begin{array}{l}\text { Game and rewards aspects of the app, Intrinsic motivation, Peer support, } \\
\text { Reminder, Calendar, Appointment scheduling }\end{array}$ & 20 \\
\hline Engagement & Engagement, Video / Audio, Feedback and Response time & 20 \\
\hline Security and Privacy & Security and privacy & 18 \\
\hline Data management & $\begin{array}{l}\text { Data sharing, Data export, Data backup, History, Data graphing, Daily } \\
\text { reports }\end{array}$ & 15 \\
\hline Undesirable events & $\begin{array}{l}\text { How bothersome the daily prompts were, Undesirable events, Commercial } \\
\text { links, In-app purchases }\end{array}$ & 9 \\
\hline
\end{tabular}

Characteristics of assessors and procedures

Table 4 shows the procedures and assessors' characteristics. For the purposes of this review, the assessors were defined as the person who evaluated or assessed the quality of mobile health apps. The majority of studies (38 studies, $55 \%$ ) used experts (health professionals or researchers) as assessors only. The numbers of expert assessors ranged from 2 - 28 (Mean 4.0 $\mathrm{SD}$ 5.2) and the most common number was 2 (24 studies). The numbers of lay person assessors ranged from 5 - 3,977 (Mean 202.3 \pm SD 731.5), the most common number were 14, 22, 30 and 52 ( 2 studies each)

Furthermore, in 59 studies ( $85 \%$ ), the app contents were downloaded for quality assessment while in 10 studies (15\%), only the contents on the description page of the app were assessed.

Additionally, most of the studies did not report duration of time to use the apps before assessment (47 studies, $68 \%$ ). The maximum duration was 6 months in the study which assessed a healthy diet app [56], while the minimum duration was 5-10 $\mathrm{min}$ in the study of a drug information app [64]. Three studies (4\%) did not specify the duration of usage (e.g. for some time, several weeks or a few days).

In addition, questionnaires were the only most commonly used methods to collect data in the process of quality assessment (65 studies, $94 \%$ ). Fifty four studies (78 \%) did not report psychometric properties of the questionnaires or assessment tools.

\section{Quality and risk of bias}

Based on the quality and risk of bias checklist by BinDhim et al. (2015) [11], the scores ranged from $4 / 8$ to $8 / 8$ (Mean $5.9 \pm$ SD1.2). The most common score was 5 (24 studies, $35 \%$ ), the maximum score was 8 (9 studies, $13 \%$ ) and the minimum score was 4 (7 studies, $10 \%$ ). Most of the studies clearly described the method of appraisal of an app's quality ( 68 studies, $99 \%$ ) and clearly identified the target groups of users (69 studies, $100 \%$ ). A higher score represented lower risk of bias and higher quality of the studies [11]. 
http://wjst.wu.ac.th

Table 4 Characteristics of Procedures and Assessors.

\begin{tabular}{|c|c|}
\hline Characteristics & Number of studies $(n=69)$ \\
\hline \multicolumn{2}{|l|}{ Assessors } \\
\hline Lay person users only & 24 \\
\hline Experts only & 38 \\
\hline Lay person users and experts & 5 \\
\hline Experts and developers & 1 \\
\hline Experts, developers, and lay person users & 1 \\
\hline \multicolumn{2}{|l|}{ Tools for collecting data } \\
\hline Interview guide only & 3 \\
\hline Questionnaires only & 65 \\
\hline Interview and questionnaires & 1 \\
\hline \multicolumn{2}{|c|}{ Duration of the apps usage before assessment } \\
\hline 6 months (maximum) & 1 \\
\hline 3 months (most common) & 3 \\
\hline 7 days (most common) & 3 \\
\hline 4 days & 1 \\
\hline $5-10$ min (minimum) & 1 \\
\hline Others & 10 \\
\hline Not specified & 3 \\
\hline Not reported & 47 \\
\hline \multicolumn{2}{|c|}{ Downloading apps' contents } \\
\hline Downloaded & 59 \\
\hline Not downloaded & 10 \\
\hline \multicolumn{2}{|c|}{ Psychometric properties of questionnaires or assessment tools } \\
\hline No reported & 54 \\
\hline Reliability tests only & 10 \\
\hline Validity and reliability tests & 5 \\
\hline
\end{tabular}

\section{Discussion}

Quality assessment criteria of mobile health apps

We grouped 441 quality assessment criteria into 15 domains. Nine criteria could not be classified into any domain as these criteria were used to evaluate specific features of the apps. In 2017, Baumel et al. reviewed key criteria related to the evaluation of user-facing eHealth programs. Using information from all types of eHealth programs, Baumel's 454 criteria were grouped into 11 domains [68]. Despite the difference in the included studies, our study focused on mHealth apps and found almost similar in the number and contents of the assessment criteria.

The 15 domains for quality assessment criteria of health apps were presented. However, the classification of criteria into each domain might overlap. For instance, the concept of "Usability" is not straightforward [69]. In our findings we believe that "Usability" means more than just "Ease of use". Usability includes efficient, effective, engaging, error tolerant, and easy to learn [70]. Some health apps might be easy to use but the users cannot achieve specified goals of their health from using the apps. On the other hand, users might believe that a health app has potential to deliver some health benefits, at the same time find the app too difficult to use. Hence, the performance benefits of usage are outweighed by the effort of using the app. Unlike Baumel et al. [68] that grouped "Ease of use" into "Usability" domain, we have decided to separate these 2 domains in this study. "Ease of use" in this study is defined as "users might want only little guidance through any procedures". Likewise, the definition "Usability" is based on the ISO 9241 standard which means "The extent to which a product can be used by specified users to achieve specified goals with effectiveness, efficiency, and satisfaction in a specified context of use" [70]. 
http://wjst.wu.ac.th

In addition, the "Undesirable events" domain considers interfering events that might occur during the use of mHealth apps. However, Baumel et al. [68] did not report an "Undesirable events" domain to evaluate eHealth programs. We believe that the "Undesirable events" domain should be targeted for mobile health apps quality assessment because interfering events may interrupt users with biased or misleading information. For instance, when an advertisement pops-up to sell some health care products, users might believe that the products are trustworthy as they were recommended to use by the apps.

Five recommended steps for research on quality assessment of mobile health apps

Our review suggests that researchers who are interested in the quality assessment of mobile health apps should follow these 5 key steps in order to conduct a concrete apps assessment (Figure 2). All recommendations are based on the data gathered from included studies.

Step 1: Select appropriate category and the number of assessors to assess the quality of the apps. The exact target groups of the apps should be defined whether the apps were developed for patients/lay person users, health care providers, or both because the quality assessment criteria will be specific to their use. In addition, the number of assessors might differ in each assessor category. The number of expert assessors should be 2 - 4 persons. The number of lay person assessors in the pilot or early stage of app development should be between 15 - 50 persons and in the later stage of app development should be 200 persons.

Step 2: Determine appropriate usage duration of the apps prior to performing quality assessment. The assessors need time to use the apps before an assessment can be made. The duration of usage depends on the functions, and goals of the apps. We recommend 7 days for general health apps and 3 months for the apps. In other words, apps require long term use to see their results.

Step 3: The app's contents must be downloaded into the device for quality assessment. Descriptive information shown in the apps marketplaces are insufficient for assessing the quality of the apps [11].

Step 4: An appropriate quality assessment tool must be chosen. In order to assess the quality of mobile health apps, it is important to evaluate its psychometric properties. Questionnaires are the most commonly tools used to assess the quality of the apps. Several included studies did not report psychometrics properties for questionnaires or assessment tools. The questionnaires or assessment tools used in these studies might be lacking in reliability (consistency of the measurement process) and validity (measurement of what it is supposed to be measured) which could lead to poor quality data and misleading conclusions [51,71]. The questionnaires with acceptable levels of validity and reliability can present what they claim to measure with consistent results from repeated samples and different researchers over time [72].

There are two possible alternatives for this step: First, the researchers can create a set of their own quality assessment criteria in a new questionnaire with acceptable levels of validity and reliability. The quality assessment criteria should cover 15 quality domains presented in this review. The second alternative is to use valid, reliable, existing questionnaires. However, these questionnaires should be available in the same language and culture that are used by the assessors [73].

Step 5: Assess the app using a well-designed questionnaire then interpret the quality of the app and consider the scores from the questionnaires. 
http://wjst.wu.ac.th

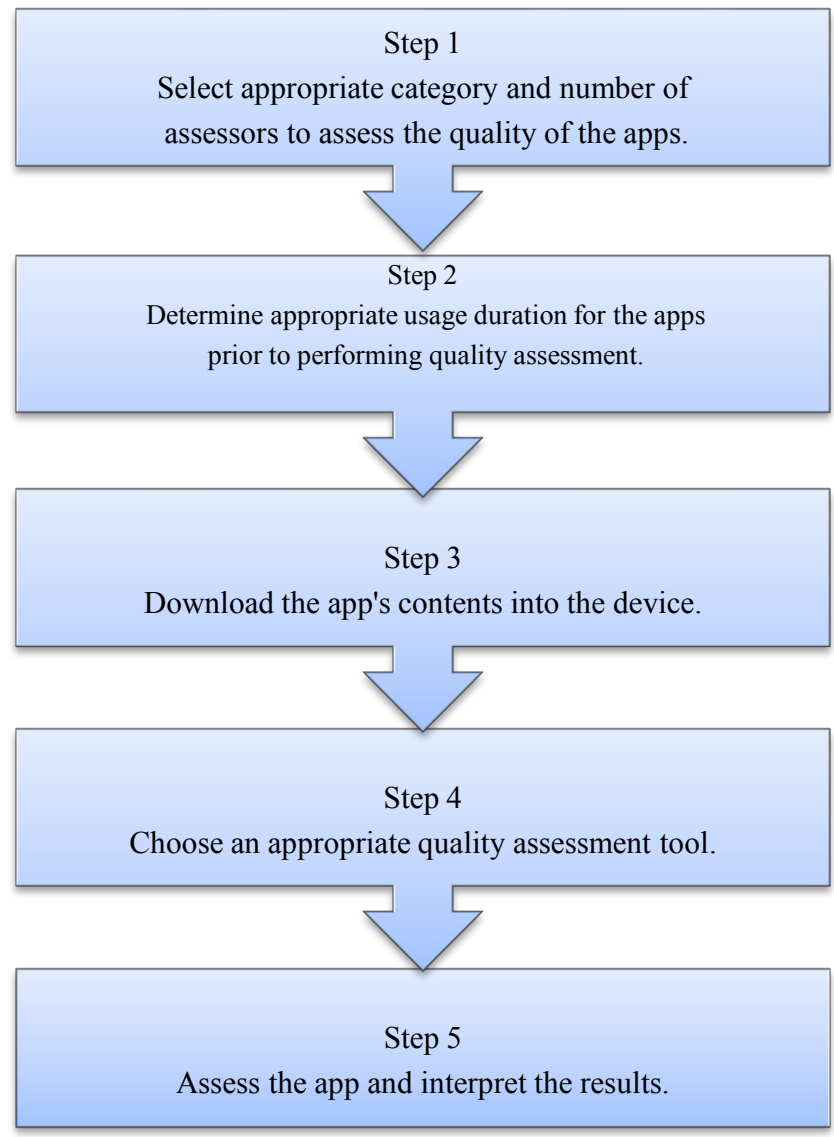

Figure 2 Five recommended steps for a research on quality assessment of mobile health apps.

\section{Limitations}

One of the limitations of this study is the lack of details in reported information from the included studies such as the duration of usage before assessment, method to select the apps for assessment and method used to assess the apps. Such details can contribute to the improvement of assessment methods for mHealth apps in the future. Furthermore, this systematic review included only studies published in English and did not focus on language and cultural differences among the studies. Most mHealth apps aim for changing the user's quality of life to improve their health behavior. Language used in the questionnaire and cultural differences may contribute to the value that may be of concern to the app users. Future work is needed to further explore some important assessment criteria that might be different among languages and cultures.

\section{Conclusions}

The 15 domains of quality assessment criteria for mobile health apps were identified. Our review suggests that the researches and developers should apply these 15 domains in their mobile health apps development process or develop new assessment criteria based on the 15 domains for users to assess quality of mobile health apps themselves. However, the 15 domains are suitable for the general assessment criteria of mobile health apps. Many types of apps aim to benefit the health and wellness of users with a wide variety of features and functions. Further research should be focusing on identifying 
http://wjst.wu.ac.th

specific criteria for a specific type of apps. Furthermore, the 5 recommended steps for the research on quality assessment of mobile health app are presented.

\section{Acknowledgements}

We thank the Division of International Affair and Language Development (DIALD), Naresuan University for technical and language editing of the manuscript.

\section{References}

[1] Research2guidance. mHealth Economics 2017-Current Status and Future Trends in Mobile Health. Available at: https://research2guidance.com/product/mhealth-economics-2017-current-status-andfuture-trends-in-mobile-health, accessed January 2018.

[2] MobiHealthNews. US Regulators Remove Two acne Medical Apps. Available at: http://www.mobihealthnews.com/13123/us-regulators-remove-two-acne-medical-apps, accessed January 2018.

[3] AP Demidowich, K Lu, R Tamler and Z Bloomgarden. An evaluation of diabetes self-management applications for Android smartphones. J. Telemed Telecare 2012; 18, 235-8.

[4] FDA. Mobile Medical Applications. Available at: https:/www.fda.gov/MedicalDevices/ DigitalHealth/MobileMedicalApplications/default.htm, accessed January 2018.

[5] AJ Barton. The regulation of mobile health applications. BMC Med. 2012; 10, 46.

[6] Psyberguide. App Guide. Available at: https://psyberguide.org/apps, access January 2018.

[7] American Psychiatric Association. App Evaluation Model. Available at: https://www.psychiatry.org /psychiatrists/practice/mental-health-apps/app-evaluation-model, accessed January 2018.

[8] P Auger. Information Sources in Grey Literature (Guides to Information Sources). ${ }^{\text {th }}$ ed. De Gruyter Saur, Berlin, 1998, p. 177.

[9] D Moher, A Liberati, J Tetzlaff, DG Altman and the PRISMA Group. Preferred reporting items for systematic reviews and meta-analyses: The PRISMA statement. J. Clin. Epidemiol. 2009; 62, 100612.

[10] Cochrane. What is a Systematic Review? Available at: http://consumers.cochrane.org/whatsystematic-review, accessed January 2018.

[11] NF BinDhim, A Hawkey and L Trevena. A systematic review of quality assessment methods for smartphone health apps. Telemed. J. E. Health 2015; 21, 97-104.

[12] JPT Higgins, S Green and Cochrane Collaboration. Cochrane Handbook for Systematic Reviews of Interventions, c2008. John Wiley \& Sons Ltd, Hoboken, 2008, p. 118-42.

[13] LC Abroms, N Padmanabhan, L Thaweethai and T Phillips. iPhone apps for smoking cessation: A content analysis. Am. J. Prev. Med. 2011; 40, 279-85.

[14] IM Lopes, BM Silva, JJPC Rodrigues, J Lloret and ML Proença. A mobile health monitoring solution for weight control. In: Proceedings of the International Conference on Wireless Communications and Signal Processing. Nanjing, China, 2011, p. 1-5.

[15] BA Rosser and C Eccleston. Smartphone applications for pain management. J. Telemed. Telecare 2011; 17, 308-12.

[16] R Heinonen, R Luoto, P Lindfors and CH Nygard. Usability and feasibility of mobile phone diaries in an experimental physical exercise study. Telemed. J. E. Health 2012; 18, 115-9.

[17] K Huckvale, M Car, C Morrison and J Car. Apps for asthma self-management: A systematic assessment of content and tools. BMC Med. 2012; 10, 144.

[18] H Kharrazi, R Chisholm, DV Nasdale and B Thompson. Mobile personal health records: An evaluation of features and functionality. Int. J. Med. Inform. 2012; 81, 579-93.

[19] HA Kurdi, A Alkhowaiter, A Al-Muaibed, B Alotaibi, R Alhaweal and T Alotaibi. myPDA: A Mobile Healthcare Application for Personal Diet Assisting. In: Proceedings of the International Conference on Advanced Computer Science Applications and Technologies. Kuala Lumpur, Malaysia, 2012, p. 491-6. 
http://wjst.wu.ac.th

[20] SO Neill and RR Brady. Colorectal smartphone apps: Opportunities and risks. Colorectal Dis. 2012; 14, e530-e534.

[21] B Sheehan, Y Lee, M Rodriguez, V Tiase and R Schnall. A comparison of usability factors of four mobile devices for accessing healthcare information by adolescents. Appl. Clin. Inform. 2012; 3, 356-66.

[22] MRC Cuenca, MDC Cuenca and RM Verdugo. Availability and medical professional involvement in mobile healthcare applications related to pathophysiology and pharmacotherapy of HIV/AIDS. Eur. J. Hosp. Pharm. 2013; 20, 356-61.

[23] B Martinez-Perez, IDL Torre-Diez, S Candelas-Plasencia and M Lopez-Coronado. Development and evaluation of tools for measuring the quality of experience (QoE) in mHealth applications. $J$. Med. Syst. 2013; 37, 9976.

[24] KE Muessig, EC Pike, S Legrand and LB Hightow-Weidman. Mobile phone applications for the care and prevention of HIV and other sexually transmitted diseases: A review. J. Med. Internet Res. 2013; 15, 19-40.

[25] A Pandey, S Hasan, D Dubey and S Sarangi. Smartphone apps as a source of cancer information: Changing trends in health information-seeking behavior. J. Cancer Educ. 2013; 28, 138-42.

[26] JN Stinson, LA Jibb, C Nguyen, PC Nathan, AM Maloney, LL Dupuis, JT Gerstle, B Alman, S Hopyan, C Strahlendorf, C Portwine, DL Johnston and M Orr. Development and testing of a multidimensional iPhone pain assessment application for adolescents with cancer. J. Med. Internet Res. 2013; 15, e51.

[27] YZ Wang, YG He, G Mitzel, S Zhang and M Bartlett. Handheld shape discrimination hyperacuity test on a mobile device for remote monitoring of visual function in maculopathy. Invest. Ophthalmol. Vis. Sci. 2013; 54, 5497-504.

[28] M Arnhold, M Quade and W Kirch. Mobile applications for diabetics: A systematic review and expert-based usability evaluation considering the special requirements of diabetes patients age 50 years or older. J. Med. Internet Res. 2014; 16, e104.

[29] L Bhachu, LN Soldatova, I Spasić and K Button. Mobile application Knee Care to support knee rehabilitation. In: Proceedings of the Science and Information Conference. London, England, 2014, p. 447-51.

[30] MR Cantudo-Cuenca, MA Robustillo-Cortes, MD Cantudo-Cuenca and R Morillo-Verdugo. A better regulation is required in viral hepatitis smartphone applications. Farm. Hosp. 2014; 38, 112-7.

[31] MJ Cho, JL Sim and SY Hwang. Development of smartphone educational application for patients with coronary artery disease. Healthc. Inform. Res. 2014; 20, 117-24.

[32] K Connor, RR Brady, A de Beaux and B Tulloh. Contemporary hernia smartphone applications (apps). Hernia 2014; 18, 557-61.

[33] B Cruz Zapata, A Hernández Niñirola, A Idri, JL Fernández-Alemán and A Toval. Mobile PHRs compliance with Android and iOS usability guidelines. J. Med. Syst. 2014; 38, 81.

[34] RDL Vega, R Roset, E Castarlenas, E Sánchez-Rodríguez, E Solé and J Miró. Development and testing of painometer: A smartphone app to assess pain intensity. J. Pain 2014; 15, 1001-7.

[35] D Dubey, A Amritphale, A Sawhney, N Amritphale, P Dubey and A Pandey. Smart phone applications as a source of information on stroke. J. Stroke 2014; 16, 86-90.

[36] ML Gilliam, SL Martins, E Bartlett, SQ Mistretta and JL Holl. Development and testing of an iOS waiting room "app" for contraceptive counseling in a Title X family planning clinic. Am. J. Obstet. Gynecol. 2014; 211, 481, e1-e8.

[37] E Jeon, HA Park, YH Min and HY Kim. Analysis of the information quality of korean obesitymanagement smartphone applications. Healthc. Inform. Res. 2014; 20, $23-9$.

[38] SR Stoyanov, L Hides, DJ Kavanagh, O Zelenko, D Tjondronegoro and M Mani. Mobile app rating scale: a new tool for assessing the quality of health mobile apps. JMIR Mhealth Uhealth 2015; $\mathbf{3}$, e27.

[39] A Sunyaev, T Dehling, PL Taylor and KD Mandl. Availability and quality of mobile health app privacy policies. J. Am. Med. Inform. Assoc. 2015; 22, e28-e33. 
http://wjst.wu.ac.th

[40] N Baghaei, D Nandigam, J Casey, A Direito and R Maddison. Diabetic Mario: Designing and evaluating mobile games for diabetes education. Games Health J. 2016; 5, 270-8.

[41] RD Capras and SD Bolboaca. An evaluation of free medical applications for Android smartphones. Appl. Med. Inform. 2016; 38, 117-32.

[42] SM Coulon, CM Monroe and DS West. A systematic, multi-domain review of mobile smartphone apps for evidence-based stress management. Am. J. Prev. Med. 2016; 51, 95-105.

[43] T Dantas, M Santos, A Queirós and AG Silva. Mobile applications in the management of headache. Proc. Comput. Sci. 2016; 100, 369-74.

[44] S Heldenbrand, BC Martin, PO Gubbins, K Hadden, C Renna, R Shilling and L Dayer. Assessment of medication adherence app features, functionality, and health literacy level and the creation of a searchable Web-based adherence app resource for health care professionals and patients. J. Am. Pharm. Assoc. 2016; 56, 293-302.

[45] D Hidalgo-Mazzei, A Mateu, M Reinares, A Murru, CDM Bonnín, C Varo, M Valenti, J Undurraga, S Strejilevich, J Sánchez-Moreno, E Vieta and F Colom. Psychoeducation in bipolar disorder with a SIMPLe smartphone application: Feasibility, acceptability and satisfaction. J. Affect. Disord. 2016; 200, 58-66.

[46] S Jo and HA Park. Development and evaluation of a smartphone application for managing gestational diabetes mellitus. Healthc. Inform. Res. 2016; 22, 11-21.

[47] JS Loy, EE Ali and KY Yap. Quality assessment of medical apps that target medication-related problems. J. Manag. Care Spec. Pharm. 2016; 22, 1124-40.

[48] ER Mangone, V Lebrun and KE Muessig. Mobile phone apps for the prevention of unintended pregnancy: A systematic review and content analysis. JMIR Mhealth Uhealth 2016; 4, e6.

[49] ML Moglia, HV Nguyen, K Chyjek, KT Chen and PM Castano. Evaluation of smartphone menstrual cycle tracking applications using an adapted APPLICATIONS scoring system. Obstet. Gynecol. 2016; 127, 1153-60.

[50] M Myint, A Adam, S Herath and G Smith. Mobile phone applications in management of enuresis: The good, the bad, and the unreliable! J. Pediatr. Urol. 2016; 12, 112.e1-112.e6.

[51] AC Powell, J Torous, S Chan, GS Raynor, E Shwarts, M Shanahan and AB Landman. Interrater reliability of mHealth app rating measures: Analysis of top depression and smoking cessation apps. JMIR Mhealth Uhealth 2016; 4, e15.

[52] U Sarkar, GI Gourley, CR Lyles, L Tieu, C Clarity, L Newmark, K Singh and DW Bates. Usability of commercially available mobile applications for diverse patients. J. Gen. Intern. Med. 2016; 31, 1417-26.

[53] SR Stoyanov, L Hides, DL Kavanagh and H Wilson. Development and validation of the user version of the Mobile Application Rating Scale (uMARS). JMIR Mhealth Uhealth 2016; 4, e72.

[54] HK Ubhi, S Michie, D Kotz, OCP van Schayck, A Selladurai and R West. Characterising smoking cessation smartphone applications in terms of behaviour change techniques, engagement and easeof-use features. Transl. Behav. Med. 2016; 6, 410-7.

[55] A Baumel, K Faber, N Mathur, JM Kane and F Muench. Enlight: A comprehensive quality and therapeutic potential evaluation tool for mobile and web-based eHealth interventions. J. Med. Internet Res. 2017; 19, e82.

[56] IDL Torre Diez, B Garcia-Zapirain, M Lopez-Coronado, JJPC Rodrigues and CDP Vegas. A new mHealth app for monitoring and awareness of healthy eating: Development and user evaluation by Spanish users. J. Med. Syst. 2017; 41, 109.

[57] T Ginossar, SF Shah, AJ West, JM Bentley, CA Caburnay, MW Kreuter and AY Kinney. Content, usability and utilization of plain language in breast cancer mobile phone apps: A systematic analysis. JMIR Mhealth Uhealth 2017; 5, e20.

[58] K Grindrod, J Boersema, K Waked, V Smith, J Yang and C Gebotys. Locking it down: The privacy and security of mobile medication apps. Can. Pharm. J. 2017; 150, 60-6.

[59] Y Guo, J Bian, T Leavitt, HK Vincent, LV Zalm, TL Teurlings, MD Smith and F Modave. Assessing the quality of mobile exercise apps based on the american college of sports medicine guidelines: A reliable and valid scoring instrument. J. Med. Internet Res. 2017; 19, e67. 
http://wjst.wu.ac.th

[60] RN Jamison, DC Jurcik, RR Edwards, CC Huang and EL Ross. A pilot comparison of a smartphone app with or without 2-way messaging among chronic pain patients: Who benefits from a pain app? Clin. J. Pain. 2017; 33, 676-86.

[61] S Leigh, J Ouyang and C Mimnagh. Effective? Engaging? Secure? Applying the ORCHA-24 framework to evaluate apps for chronic insomnia disorder. Evid. Based Ment. Health 2017; 20, e20.

[62] I Plaza García, CM Sánchez, AS Espílez, I García-Magariño, GA Guillén and J García-Campayo. Development and initial evaluation of a mobile application to help with mindfulness training and practice. Int. J. Med. Inform. 2017; 105, 59-67.

[63] T Stutz, G Emsenhuber, D Huber, M Domhardt, M Tiefengrabner, GJ Oostingh, U Fötschl, N Matis and S Ginzinger. Mobile phone-supported physiotherapy for frozen shoulder: Feasibility assessment based on a usability study. JMIR Rehabil. Assist. Technol. 2017; 4, e6.

[64] O Thinnukool, P Khuwuthyakorn and Wientong. Pharmacy assistant mobile application (PAMA): Development and reviews. Int. J. Interac. Mobile Tech. 2017; 11, 178-94.

[65] B Walter, R Schmid and SV Delius. A smartphone app for improvement of colonoscopy preparation (ColoprAPP): Development and feasibility study. JMIR Mhealth Uhealth 2017; 5, e138.

[66] C Bohme, MB von Osthoff, K Frey and J Hubner. Qualitative evaluation of mobile cancer apps with particular attention to the target group, content, and advertising. J. Cancer Res. Clin. Oncol. 2018; 144, 173-81.

[67] HS Park, H Cho and HS Kim. Development of cell phone application for blood glucose selfmonitoring based on ISO/IEEE 11073 and HL7 CCD. Healthc. Inform Res. 2015; 21, 83-94.

[68] A Baumel, ML Birnbaum and M Sucala. A systematic review and taxonomy of published quality criteria related to the evaluation of user-facing eHealth programs. J. Med. Syst. 2017; 41, 128.

[69] J Leaviss. 2010, The Role of Usability, Usefulness and Frame in Persuasive Health Communication. $\mathrm{Ph}$. D. Dissertation. University of Nottingham, Nottingham, England.

[70] Q Whitney. What does usability mean: Looking beyond 'Ease of Use', Available at: http://www.wqusability.com/articles/more-than-ease-of-use.html, accessed August 2018.

[71] M Widerszal-Bazyl and R Cieslak. Monitoring psychosocial stress at work: Development of the psychosocial working conditions questionnaire. Int. J. Occup. Saf. Ergon. 2000; 6, 59-70.

[72] K Parmenter and J Wardle. Evaluation and design of nutrition knowledge measures. J. Nutr. Educ. 2000; 32, 269-77.

[73] AK Reimers, F Mess, J Bucksch, D Jekauc and A Woll. Systematic review on measurement properties of questionnaires assessing the neighbourhood environment in the context of youth physical activity behaviour. BMC Public Health 2013; 13, 1-15. 